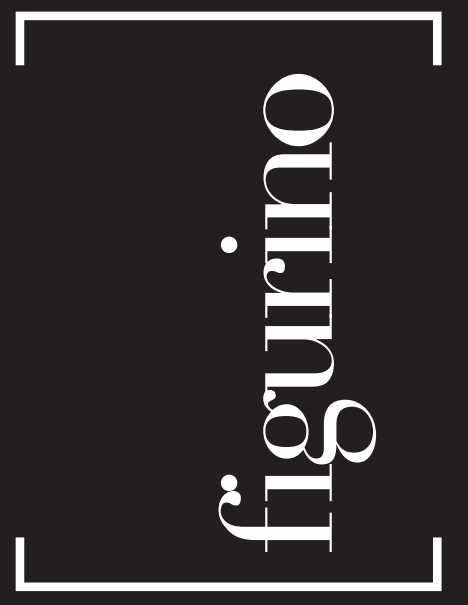

[ FAUSTO VIANA I ROSANE MUNIZ]

Fausto Viana é figurinista, cenógrafo e pesquisador. Professor livre-docente da ECA-USP.

E-mail: faustoviana@uol.com.br

Rosane Muniz é jornalista, atriz e autora do livro Vestindo os nus: o figurino em cena (Senac Rio, 2004). Mestra em Artes Cênicas (ECA-USP), mantém o blog www.vestindoacena.com. E-mail: romuniz@gmail.com

\title{
Nudez em cena: normal, provocativa... escatológica?
}

$[32$

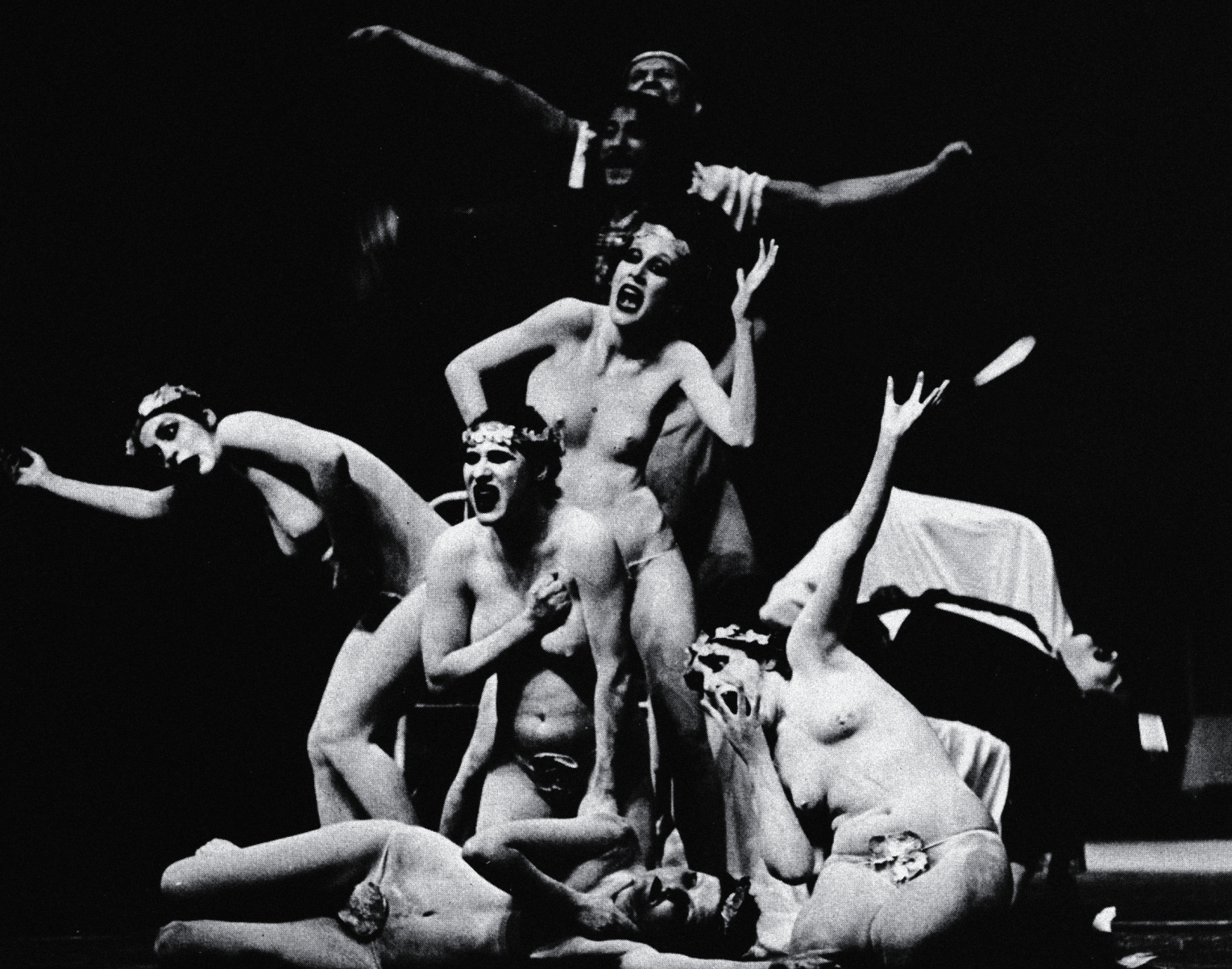


Nossa coluna desta edição se desnuda e revela tudo o que vai por baixo do figurino teatral. "Ora", dirá o leitor, "nudez em cena é supernormal"! Se pensarmos em teatro, então, e nas nossas "raízes" teatrais, quando os indígenas se tornaram parte da encenação, já em mil e quinhentos e pouco, nudez é mais do que normal, presente e aceita sem maiores consequências.

\section{Engano 1: retificação}

Ao dizer que nossa coluna vai mostrar o que está por baixo do figurino é fundamental esclarecer que, se a revelação acontecer em cena, a nudez passa a ser figurino. Em qualquer filme, peça de teatro, performance ou apresentação em que um ator se desnude, tire a roupa, fique nu, pelado ou como desejar chamar, este passa a ser um novo traje que tem um significado muito mais profundo e revelador do que se possa imaginar.

\section{Engano 2: retificação}

Nudez em cena não é "supernormal" e a maioria dos atores parece apresentar enorme dificuldade em conseguir se despir naturalmente no palco. 0 mundo contemporâneo cobra padrões estéticos quase inatingíveis para a maioria dos mortais. 0 que você acha que se cobra dos atores, em um mercado cada vez mais seletivo, competitivo e com grande oferta de mão de obra? Releia Barthes (1979), confira em João Braga (2004) e lembre que, em primeiro lugar, vestimos por proteção. Depois, por pudor. Depois e depois, por...

Oras, desnudo o ator em cena, a personagem está desprotegida. Seu pudor ficará evidente diante do seu comportamento, das ações e dos textos que terá enquanto nu.

A nudez é um intrincado conjunto de símbolos e signos, cada vez mais direcionado por padrões de tamanho (no todo e nas partes). No palco, na cena, é difícil esconder a nudez concreta, aquela do mundo real, das imperfeições. Quando a nudez é necessária, a solução é o bom senso: por que despir? Quando despir? Até que ponto despir? A nudez é adequada para a encenação?

Muitas vezes, o efeito que se deseja é muito maior com os atores com menos roupas do que sem roupas. Para isso, entre outros, vale ver o conceito de fetiche em Steele (1997) e Greene (2004).

Sugerir e insinuar em teatro têm dimensões muito mais dionisiacas do que revelar, na maioria das vezes.

\section{Engano 3: retificação}

0 teatro ao qual nossos indígenas se juntaram nos idos de 1500 era de origem vicentina, portuguesa, estabelecido dentro da tradição da Idade Média, sob intensa dominação da Igreja Católica.

Não bastasse, no sentido pudico da coisa, ser da Igreja, foi desenvolvido aqui pela Igreja, na figura do padre José de Anchieta.

Um dos companheiros de Anchieta, padre Manuel da Nóbrega, escreveu para Portugal dizendo que era preciso cobrir as vergonhas dos nativos, "as quais não eram fanadas, e as cabeleiras delas bem rapadas e feitas", e pediu que mandassem para cá quem soubesse tecer porque havia algodão'. Imagine se algum índio ia pisar em cena sem roupa?

Já viu isso como possivel na combinação entre Gil Vicente, colonizador português, sacerdotes "medievalizados" e a Santa Igreja?

Os indígenas entravam em cena vestidos da cabeça aos pés. Se fossem personagens santos, envergariam as roupas portuguesas. Mas e se fossem diabos? Vestiriam as roupas que os indígenas cultuavam nas entidades que adoravam.

As roupas de pena e palha não eram mais trajes das divindades locais, dentro do esquema do sagrado que o indígena mantinha. Esse traje passou a simbolizar o 
mal, o negativo, em suma, o demônio, cuja tarefa até então tinha sido embebedar os índios com cauim (bebida que se prepara com mandioca cozida e fermentada) e desenvolver "maus hábitos morais", entre eles: o fato de andarem nus. A essas personagens trajadas como indígenas eram contrapostos os trajes de São Lourenço, São Miguel, Nossa Senhora.

0 Brasil nunca mais seria o mesmo.

\section{Acendendo a luz}

Claro que os tempos modernos trouxeram mudanças. Se um espectador relatava que, em um teatro em 1905, em São Paulo, "os jovens de 15 a 75 anos ficaram fascinados com o maiô cor de carne que cobria o corpo todo da atriz Amélia Rentini" (AMERICANO, 1957, p. 251), hoje tudo mudou.

Os anos 1960-1970 trouxeram para a cena toda a liberdade provocativa da nudez e do amor livre entre todos e tudo. 0 espetáculo Hair (1968) terminava com os atores nus, arrancando suas roupas. Os cabelos compridos, as longas barbas e a liberdade total eram a moldura daqueles corpos "desencanados", protestando contra a guerra.

Em 1978, o espetáculo Macunaíma, do diretor Antunes Filho, trazia os corpos das índias brasileiras completamente descobertos. Na verdade, era quase nu, pois uma camada fina de pó branco cobria o corpo das atrizes.

De lá para cá são inúmeros os exemplos do uso do nu e do quase nu para construir uma cena.

Os anjos cobertos com massa de papel que ia descolando do corpo aos poucos em Paraíso perdido (1992), do Teatro da Vertigem, na Igreja de Santa Ifigênia, lembravam a proposta de Antonin Artaud, já na década de 1930, na qual pedaços de seda foram friccionados no corpo dos atores e iam se soltando ao longo do espetáculo, como uma pele que se desfaz. Ou ainda com o grupo em O livro de Jó (1995), na provocante cena de Matheus Nachtergaele como Jó, na Maternidade da Condessa Matarazzo. 0 crítico [34] Sábato Magaldi declarou: "As simplificações da montagem atendem ao desenho interno da criação de Antônio Araújo, sem desrespeitar o propósito do dramaturgo de, ao lado do auto de fé, reivindicar a legitimidade do auto profano"2.

Outro exemplo é o ator Chiquinho Brandão, em UBU pholias physicas (1985), com o Teatro do Ornitorrinco e figurino de Lina Bo Bardi.

José Celso Martinez Corrêa e seus atores do Teatro Oficina não só ficavam nus, como se masturbavam em Cacilda! (1998), o que causava horror - e sensação - em muita gente. 0 diretor-ator volta em Os sertões (2001) fecundando a terra. Grande parte do elenco trabalhava nua durante o espetáculo, em uma combinação de delicadeza com adequação rara de se ver.

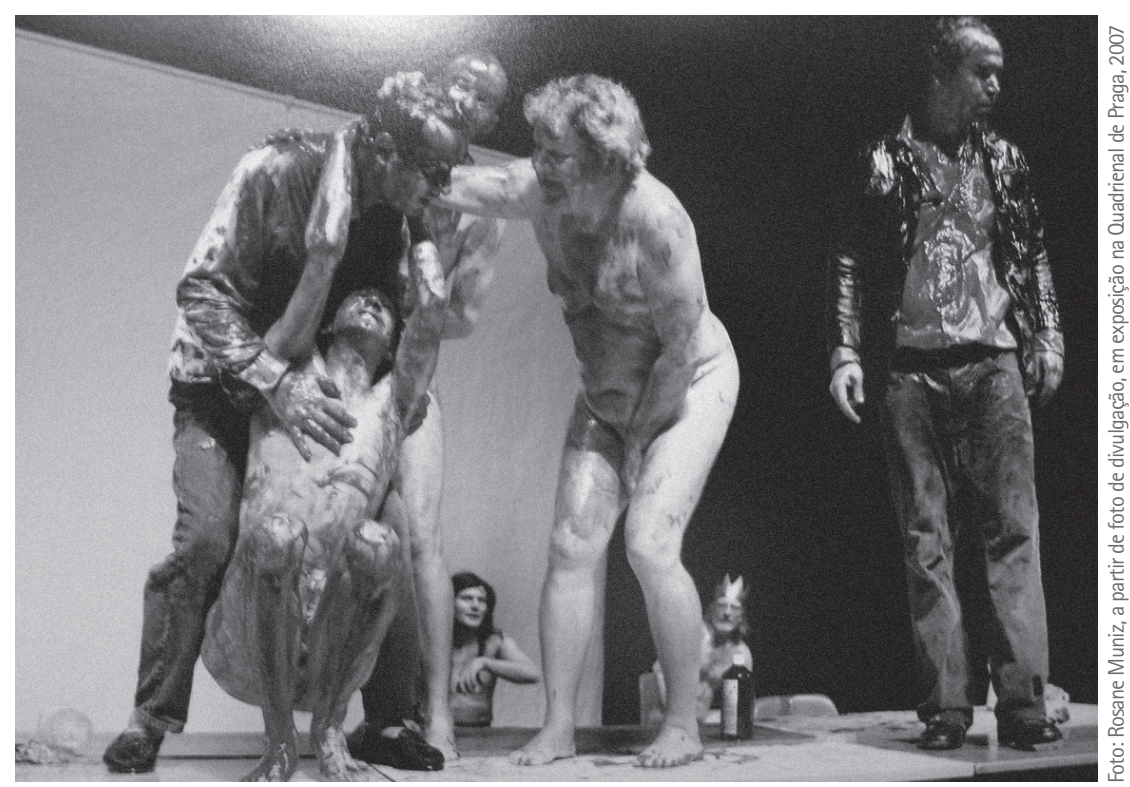

Macbeth, com direção de Jurgen Gosch, no Dusseldorf Schauspielhaus 
Ainda podemos falar da cena de nu inserida em Strindberg, na encenação de Camaradagem (2006), do Grupo TAPA, reforçando o destroçar da personagem que passa de oprimida a opressora.

E para não deixarmos de citar o cinema, que tal lembrarmos de Beleza americana (1999) e o nu com pétalas de rosas vermelhas do sonho de Lester Burham, personagem interpretado por Kevin Spacey.

No teatro alemão, a montagem do diretor Jurgen Gosch, com cenografia e figurino de Johannes Schutz, para Macbeth (2005) ganhou medalha de ouro na Quadrienal de Praga 2007 pela melhor realização de produção. Uma montagem que foi muito vaiada na Alemanha por sua irreverência em fazer um Shakespeare só com homens no elenco, nus, com uma linguagem contemporânea para o Dusseldorf Schauspielhaus.

\section{Pinturas rituais e o nu}

0 bom teatro é um rito e cada vez mais caminha de volta para isso. Mas como a questão é figurino/nudez, nunca é tarde para lembrar que as tatuagens, pinturas ou máscaras usadas no rito envolvem o corpo do praticante e se valem dele para uma função mística, que é tirar o homem do estado animal, bruto, letárgico para um estado de alteração, no qual mudanças possam ser promovidas.

Dessa maneira, a nudez passa a contribuir com cores, formas, volumes, texturas e movimentos do corpo, mas fica alterada como fator de base a cada novo elemento que é acrescentado ao corpo do performer. A nudez, assim, se transmuta, solicitando nova interpretação e julgamento do seu enquadramento em cena, já que é para 0 espetáculo como um todo que os trajes existem.

Augusto Boal, diretor teatral e criador do Teatro do Oprimido, dizia: "Faço uma imagem com os atores em cena. Quando entra o ator... é claro que ele não entra nu. Se ele entrar nu, também é o figurino. 0 corpo nu é o figurino. 0 que ele estiver em cena, vestindo, vai se relacionar com o resto" ${ }^{3}$.

\section{NOTAS}

[1] Referência à Carta de Pero Vaz de Caminha ao Rei D. Manuel. Disponivel em: <http://www.scribd. com/doc/124017/A-Carta-de-Pero-Vaz-de-Caminha>. Acesso em: 5 maio 2009.

[2] MAGALDI, Sábato. 0 livro de Jó provoca impacto. O Estado de S. Paulo, São Paulo, 24 ago 1996. Caderno 2, p. D4. Disponivel em: <http://www.itaucultural.org.br/aplicexternas/enciclopedia_teatro/ index.cfm?fuseaction=espetaculos_biografia\&tcd_verbete=302>. Acesso em: 4 maio 2009.

${ }^{[3]}$ Augusto Boal, em depoimento à Rosane Muniz, em 16 de junho de 2001.

\section{REFERÊNCIAS}

AMERICANO, Jorge. São Paulo naquele tempo (1895-1915). São Paulo: Saraiva, 1957.

BARTHES, Roland. 0 sistema da moda. São Paulo: Nacional, 1979.

BRAGA, João. História da moda: uma narrativa. São Paulo: Anhembi Morumbi, 2004.

GREENE, Robert. A arte da sedução. Rio de Janeiro: Rocco, 2004.

STEELE, Valerie. Fetiche: moda, sexo \& poder. Rio de Janeiro: Rocco, 1997. 